DOI 10.37882/2223-2982.2020.08-2.03

\title{
ДИСТАНЦИОННОЕ ОБУЧЕНИЕ ИНОСТРАННЫМ ЯЗЫКАМ В НЕЯЗЫКОВОМ ВУЗЕ: О РЕЗУЛЬТАТАХ, ТРУДНОСТЯХ И ПЕРСПЕКТИВАХ (НА ПРИМЕРЕ ФРАНЦУЗСКОГО И НЕМЕЦКОГО ЯЗЫКОВ)
}

\section{FOREIGN LANGUAGES DISTANCE LEARNING IN A NON-LINGUISTIC SCHOOL: SPEAKING ABOUT RESULTS, DIFFICULTIES AND PROSPECTS (TEACHING FRENCH AND GERMAN EXPERIENCE)}

\section{S. Bakaeva \\ E. Samorodova \\ I. Belyaeva}

Summary: Traditional distance learning until March 2020 was rather an additional option for the system of traditional full-time education, which could be used as needed. The current spontaneous pandemic situation has fully unleashed the potential of DR.

The authors of this article are discussing about the special experience of working in a distance format, especially the foreign language teaching $a$ in a non-linguistic university. They also managed to identify and comprehend the main difficulties of teaching foreign languages online, test some methods and understand the general prospects for the development of distance education, which, of course, will now firmly enter our lives.

Keywords: distance education, teaching a foreign language in a nonlinguistic university, traditional full-time education.
Бакаева София Андреевна

к.филол.н., ФГАОУ ВО «МосковскИй государственный институт международных отношений (университет) Министерства иностранных дел Российской Федерации» sophiebakaeva@gmail.com

Самородова Екатерина Александровна К.ю.Н., ФГАОУ ВО «МосковскИй государственный институт международных отношений (университет) Министерства иностранных дел Российской Федерации» e.samorodova@inno.mgimo.ru Беляева Ирина Георгиевна

к.филол.н., ФГАОУ ВО «МосковскИй государственный институт международных отношений (университет) Министерства иностранных дел Российской Федерации» irinatimakova@mail.ru

Аннотация: Традиционное дистанционное образование до марта 2020 года представляло собой скорее дополнительную опцию для системы традиционного очного, которой можно было воспользоваться по мере необходимости. Сложившаяся стихийная ситуация с пандемией полностью раскрыла потенциал ДО.

Авторы настоящей статьи говорят об особом опыте работы в дистанционном формате, а именно о преподавании иностранного языка в неязыковом вузе. Им также удалось выявить и осмыслить многие сложности преподавания иностранных языков онлайн, протестировать некоторые методики и понять общие перспективы развития дистанционного образования, которое, безусловно, отныне прочно войдет в нашу жизнь.

Ключевые слова: дистанционное образование, преподавание иностранного языка в неязыковом вузе, традиционное очное образование.
$\Pi$ андемия короновируса, так внезапно поглотившая мир в первой половине 2020 года, коснулась всех без исключения сторон жизни человека и общества. Нет ни одного сектора, который бы не претерпел тех или иных изменений. Особое испытание выпало на долю систем образования в большинстве стран мира. Очная форма обучения, подразумевающая процесс, основанный на аудиторных занятиях, проводимых в группах, в классах, в лабораториях и огромных лекционных занятиях оказалась недоступной, уступив место дистанционному образованию.

Еще в начале 90-х годов канадский исследователь Д. Шейл (Doug Shale) описал «дистанционное образование» (далее - ДО) как «примечательный парадокс»: «оно - дистанционное образование - утвердило своё суще- ствование, но оно не может найти себе определения». [1] Эта меткая характеристика актуальна и по сей день: новые технологии, а вместе с ними и методика преподавания развиваются столь стремительно, что зафиксировать единое каноническое толкование данного термина довольно сложно. Интересным на взгляд авторов является определение данное ЮНЕСКО: «учебный процесс, при котором обучающий и обучаемый отделены друг от друга временем и пространством»[2]. В «Толковом словаре терминов понятийного аппарата информатизации образования» дистанционное обучение [8] трактуется как «процесс передачи знаний, формирования умений и навыков при интерактивном взаимодействии как между обучающим и обучающимся, так и между ними и интерактивным источником информационного ресурса, отражающий все присущие учебному процессу ком- 
поненты (цели, содержание, методы, организационные формы, средства обучения), осуществляемый в условиях реализации средств ИКТ» [3]

В современной педагогической науке существует значительное количество работ российских и зарубежных исследователей, посвященных как общей концепции дистанционного обучения, так и его применения на практике: Пантелеева Т.В. и Затонский А.В. Нагаева И.А., Шевченко О.И., Сарафанов А.В., Чибисова Е.Ю, Ивко В.И., Birova J. Perraton, H., Potashnik и многие другие. Мнения коллег во многих вопросах разнятся, тем не менее они единодушны (и авторы данной работы разделяют их позицию) в том, что дистанционное образование - это довольно богатый комплекс образовательных услуг, который посредством новых технологий позволяет осуществлять широкий обмен информацией в целях приобретения знаний в различных сферах. Формы дистанционного образования довольно разнообразны и могут быть представлены в виде открытых аудио и видео чатов, видео уроков, конференций и мн. др.

Традиционное дистанционное образование до марта 2020 года представляло собой скорее дополнительную опцию для системы традиционного очного образования, которой можно было воспользоваться по мере необходимости. Сложившаяся стихийная ситуация с пандемией позволила более широко раскрыть потенциал дО.

Авторы настоящей статьи говорят об особом опыте работы в дистанционном формате, а именно о преподавании иностранного языка в неязыковом вузе. В качестве примера рассматривается Московский государственный институт (Университет) международных отношений (МГИМО). Авторам удалось выявить и осмыслить многие сложности преподавания иностранных языков онлайн, протестировать некоторые методики и обозначить общую тенденцию развития дистанционного образования, которое, безусловно, отныне прочно войдет в нашу жизнь.

Само по себе преподавание иностранного языка в дистанционном виде развивается довольно давно, а известный исследователь в области образования X. Перратон (Hilary Perraton) даже называет такой формат безоговорочно «эффективным»[4]. Наличие равного количества преимуществ и недостатков такого подхода очевидно, и они напрямую зависят от конкретной формы удалённого взаимодействия обучающего и обучающегося. Например, один из самых популярных порталов открытого образования Coursera предлагает курсы французского языка на уровне В1 в формате предзаписанных видео по избранным темам. В качестве промежуточного контроля учащимся необходимо пройти тест с автоматической проверкой. Прямая консультация с преподавателем отсутствует, учащемуся лишь предоставлен доступ к форуму, где он может обсудить свои вопросы с другими студентами и модератором. Степень эффективности такого метода работы вызывает дискуссии, и его оценка зависит от исследования индивидуальных потребностей каждого обучающегося. Кроме того, в более унифицированной университетской среде преподавания иностранных языков также встречаются различные спорные методы удалённой работы. Распространена модель, при которой преподаватель высылает студентам список тем, которые они должны пройти самостоятельно, а также список письменных упражнений, которые студент должен выполнить и переслать преподавателю до установленной даты, чтобы позже в письменном виде получить обратно проверенную работу.

Вопрос исследователей «Является ли такой подход удачным?» также не имеет однозначного ответа и требует отдельного детального рассмотрения, тем более что в период пандемии исследование развития методики преподавания на дистанте представляется наиболее актуальным. Однако, даже такие форматы дистанционного обучения иностранным языкам имеют свои преимущества: гибкость рабочей среды, в которой учащийся получает свободу выбора действий, темпа и графика, возможность более комфортного и глубокого (перцептивного) погружения в учебный материал, динамичность учебного контента, который учащийся при желании может расширять с помощью сторонних информационно-компьютерных технологий (дополнительные языковые сайты, тренажёры и приложения, интернет-словари, аудио/ видео-ресурсы, еtc) и так далее.

Если же взять за основу то, что у преподавателя и учащегося есть возможность использовать в максимальном объеме все доступные ресурсы ИКТ (Интернет-конференции, мгновенное онлайн-общение, видео, аудиоресурсы, etc), то список преимуществ дистанционного обучения значительно расширяется. При наличии стойкого видео-соединения в приложении для онлайн-конференций (допустим, Zoom или Google Hangouts), а также соответствующей методической подготовленности преподавателя (продуманный план урока, тематические презентации, видео/аудио-упражнения, умение пользоваться виртуальной доской и чатом) и, безусловно, вовлечённости студентов (включенные видео и аудио, ответственный подход к работе) процесс дистанционного обучения может быть максимально приближен к формату реального урока. Более того, видео-конференция подразумевает быстрый прямой контакт со студентом (индивидуально и в группе), оперативное сотрудничество, сиюминутный обмен материалами, привлечение современных программных и технических средств для более доступной подачи материала. Учитывая, что большинство нынешних студентов визуалы и аудиалы [5] их восприятие информации, подкреплённое аудио и видеорядом, становится более персонифицированным 
и эффективным [6]. Определенного успеха в работе со студентами позволяют добиться новейшие технические средства, которые мы опишем, частично опираясь на классификацию, предложенную А.В. Сарафановым [7]

- неинтерактивные технологии (подготовленные печатные, pdf-/doc-, аудио-, видеоматериалы, подкасты, вебинары);

- текстовое взаимодействие (электронная почта, whatsapp и прочие мессенджеры, блоги, социальные сети, форумы, чаты, Google classroom);

- видео-лекции в онлайн-формате (без прямого взаимодействия с аудиторией);

- аудио-, видеоконференции (семинары) с пространством для обмена информацией, проводимые на различных платформах (Skype, Zoom, Google Hangouts, Discord, Whereby и т.д.);

- массовые публичные онлайн-курсы (МОOК) (Coursera, Открытое образование, Udacity, Moodle и т.д.) и образовательные сайты;

- мобильные приложения.

Авторы данной статьи в своей работе со студентами 1-4 курсов МГИМО (дистанционное изучение французского и немецкого языков) обращались, в основном, к видеоконференциям и текстовому взаимодействию со студентами, сопровождая процесс обучения всевозможными дополнительными не интерактивными технологиями.

Со студентами, изучающими французский язык как основной на уровне А2 - В1, видеоконференции (80 минут) проводились 5 раз в неделю, со студентами, изучающими французский язык в качестве второго на уровне А2-В1 - видеоконференции (80 минут) проводились 3 раза в неделю. Все без исключения занятия были проведены в формате онлайн-семинара на платформе ZOOM, для каждой группы был создан чат в WhatsApp для мгновенного обмена срочной информацией, а также были созданы Google Classrooms, где публиковались все необходимые учебные материалы, домашние задания, а также работы студентов. Базовый учебник и рабочая тетрадь к нему, предусмотренные программой, при переходе на дистант остались прежними - Le Français. ru A2 (Е.Б. Александровская, Н.В. Лосева, Л.Л. Читахова) Le Français.ru B1 (Е.Б. Александровская, Н.В. Лосева, О.Е.Манакина) Для изучающих французский как первый язык в электронную форму была переведена рабочая тетрадь, каждый урок из которой отдельно публиковался в Classroom, учащиеся выполняли все задания поурочно согласно семестровому плану без скидки на сменившийся режим работы. Изучающие французский язык как второй выполняли задания из рабочей тетради выборочным образом. Для оптимизации процесса усвоения материала все грамматические и лексические правила, а также упражнения к ним были преобразованы в формат презентаций. Аудио-упражнения из учебника выполнялись в полном объеме во время урока, видео-упражнения задавались, преимущественно, на дом. Основные проблемы возникали с таким неотъемлемым типом работы как пересказ или реферирование текста. Во-первых, нестабильное интернет - соединение, рассинхронизация звука и видео-связи логичным образом мешали не только устным ответам студентов (в том числе, отработке ситуативных упражнений и диалогов), но и временами затрудняли весь процесс в целом. Вовторых, любое упражнение, подготовленное заранее и исключающее спонтанное высказывание, ставилось под сомнение в силу ряда психологических причин: у студента всегда присутствует шанс и соблазн воспользоваться определенными уловками для улучшения своего ответа, в то время как преподавателю приходится изобретать всё новые и новые виды промежуточного контроля даже для тех упражнений, которые ранее этого не требовали. Это же относится и к письменным работам: к сожалению, классические задания на перевод фраз с русского на французский/немецкий язык были многократно саботированы использованием автоматических интернет-переводчиков.

Нельзя не отметить, что в организации уроков преподаватели кафедр французского и немецкого языков могли реализовывать практически все методы преподавания иностранных языков, которые они использовали при очном обучении: дискуссия, круглый стол, ролевая игра, деловая игра, имитационная игра, учебная фирма, тандем, кооперативное обучение, дилемма, кейс-стади, методы мнемотехники, проектный, SCRUM, мозговой штурм.

Удачной системой для самостоятельной отработки лексических и грамматических навыков уровней А1-B1 можно назвать систему Moodle. В этой системе студенты получили возможность самостоятельно учить, закреплять, тренировать грамматический и лексический материал при помощи созданных на этой платформе тестовых заданий. Все студенты оценили данный вид деятельности, который повысил их оценки за текущий, промежуточный и итоговый контроль, как в высшей степени эффективный. Для тренировки, закрепления лексического и грамматического материала преподавателями кафедры немецкого языка были созданы следующие задания:

- Выберите один или несколько правильных ответов из заданного списка

- Выберите пропущенные слова

- Переведите предложение с русского языка на немецкий

- Составьте предложение из слов

- Найдите соответствие (управление глагола, формы глагола, ед/мн. число, род, синонимы/антонимы

- Вставьте в текст пропущенные слова

- Преобразуйте активный залог в пассивный и наоборот. 
Помимо платформы Moodle, хочется отметить платформу lingust.ru, основным преимуществом которой является очень богатый спектр грамматических упражнений, необходимых для выполнения при изучении основ французского языка онлайн. Для студентов начального уровня предложена платформа tapis.com, содержащая объемный грамматический материал и тренировочные упражнения, формирующие понимание речи на слух, а также les-verbes.com - платформа для обучения спряжению французских глаголов, которые всегда вызывают трудности у студентов. Для контроля приобретенных знаний можно также использовать hosgeldi.com.

Студентам уровня А2-B1, умеющим и любящим читать можно предложить взять на вооружение платформy polarfle.com (обучение языку на чтении детективных историй), а также bbc.co.uk (видеорепортажи Ma France канала ВВС по всей Франции). Данные платформы вызвали несомненный интерес студентов всех направлений подготовки МГИМО.

Использование дО в работе преподавателя очень обогащает учебный процесс, превращая уроки (например страноведения) в увлекательные путешествия. Кроме того, благодаря некоторым платформам, преподаватель сам может создавать он-лайн свои курсы и программы. Для подобной работы можно использовать платформы Online Test Pad, Udemy, Flora LMS, Stepik (cм. https://www.eduneo.ru/7-platform-dlya-sozdaniya- sobstvennogo-onlajn-kursa, https://www.eduneo.ru/3besplatnye-sistemy-distancionnogo-obucheniya-obzor/ ) и другие.

ДО, по мнению большинства преподавателей МГИMO, несмотря на имеющиеся минусы, о которых было упомянуто выше, обладают рядом неопровержимых преимуществ, предоставляют широкое поле для творчества и развития и по праву могут активно использоваться в качестве альтернативных. Одним из самых важных плюсов является доступность практически любого материала. При условиях хорошего и устойчивого подключения к Интернету у каждого обучающегося есть возможность стать слушателем любого курса и программы по иностранному языку. Условия посещения подобных занятий, безусловно, оговариваются с авторами и организаторами. Но, находясь в Москве или в Сургуте и Сызрани, можно стать слушателем интернет-уроков китайского языка университетов Парижа, Пекина или Берлина. Это привлекает обучающихся, но нельзя забывать, что очная форма обучения, базирующаяся на аудиторных занятиях, на прямом взаимодействии с преподавателем и участниками группы и иных особенностях, и нюансах, является основой стабильного и качественного языкового образования. А ДО во всех видах, в которых они есть на сегодняшний день, в перспективе могут служить, как было сказано выше, качественным дополнением для эффективности и оптимизации учебного процесса.

\section{ЛИТЕРАТУРА}

1. Doug Shale (1988) Concepts: Toward a reconceptualization of distance education, American Journal of Distance Education, 2:3, 25-35, D0I: 10.1080/08923648809526633]

2. Carlsen A., Holmberg C. , Neghina, C., Owusu-Boampong A. Closing the gap: opportunities for distance education to benefit adult learners in higher education. Hamburg: UIL, 2016. P. 106 (113) URL: https://unesdoc.unesco.org/ark:/48223/pf0000243264 (Дата обращения: 30.06.20).

3. Толковый словарь терминов понятийного аппарата информатизации образования / составители И.В. Роберт, Т.А. Лавина. - М.: БИНОМ. Лаборатория знаний, 2012. -69 с.

4. Perraton, H., Potashnik, M. Teacher education at a distance // Education and Technology Technical Notes Series, Vol. 2, No. 2, 1997. P.39.

5. Чибисова Е.Ю. Обучение иностранному языку с учетом модальностей восприятия студентов // Психология и педагогика: методика и проблемы практического применения. 2010. №13. URL: https://cyberleninka.ru/article/n/obuchenie-inostrannomu-yazyku-s-uchetom-modalnostey-vospriyatiya-studentov (дата обращения: 01.07.2020).

6. Воробьева Т.А. Психологические особенности электронного обучения // Сибирский педагогический журнал. 2015. №2. С.100

7. Сарафанов А.В. Интерактивные технологии в дистанционном обучении. Электронное учеб.-метод. Пособие. Красноярск: ИПЦ КГТУ. $2006 .-132$ с

8. Пьянников М.М. К вопросу о понятиях «Дистанционное обучение» и «Дистанционное образование» // Гуманитарный вектор. Серия: Педагогика, психология. 2010. С.41-45 